تاثير المستخلصات الميثانولية الخام لبعض النباتات ضد بعض البكتريا السالبة الممرضة

\title{
The Effect of different crude methanolic extracts against some gram negative pathogenic bacteria
}

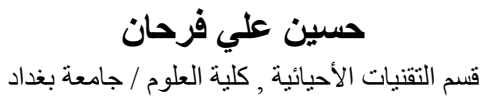

Hussien Ali Farhan

Biotechnology Dep. College of Science, Baghdad University

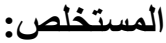

Punica ، أجريت هذه الاراسة لتقدير التاثيرالتثبطي لمستخلصات الخام (الميثانولية) لقشور الرمان

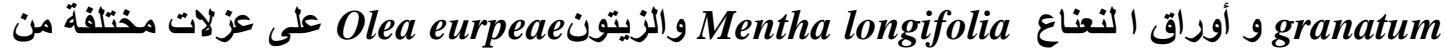

البكتريا الممرضة السالبة لصبغة كرام متمثلة بـ Serratia ، Pseudomonas aerugenosa

إذ Klebsiella pnemunoniae ، Proteus vulgaris ، Escherichia coli ، marcesens استخدمت طريقة الانتثار بالحفر لمعرفة القرة التثبية للمستخلصات أعلاه تجاه النمو البكتيري ـ أظهرت النتائج وجود تباين في تحس الأنواع البكتيرية اذ لوحظ أن بكتريا Pseudomonas aerugenosa أكثر

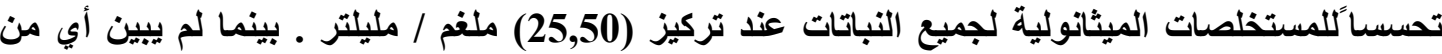

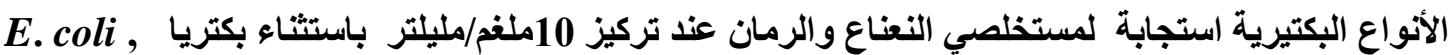
Pseudomonas aerugenosa عند تركيز 10ملفم / مليلتر . ع ع

Abstract

QThis present study was conducted to evaluated the antibacterial activity of crude extracts (Methanolic) of punica granatum peel, Menthe longifolia and Olea eurpeae leaves against some gram negative bacteria like Pseudomonas aerugenosa, Serratia marcesens, Escherichia coli, Proteus vulgaris, Klebsiella pnemunoniae. The Agar-well diffusion was used to know the ability of inhibititory of crude extracts against bacteria. Results showed different susceptibility response of bacteria under study. It was observed that Pseudomonas aerugenosa the most susceptible to Methanolic extracts to all plants in $(25,50) \mathrm{mg} / \mathrm{ml}^{-1}$ concentrate. While the bacterial strains shown no responding against mint and pomegranate extracts in $10 \mathrm{mg} / \mathrm{ml}^{-1}$ except Pseudomonas aerugenosa and Escherichia coli, was inhibited with Olive extracts only. That ability to inhabitation less in concentrate $10 \mathrm{mg} \mathrm{ml}^{-1}$.

استخدمت العديد من المضادات الحيوية التقليدية في معظم دول العالم ومنها العر اق , حيث جربت بطرق أساسية وبنسب ثابتة , و على الرغم من تللك النجاحات الكبيرة التي قدمتها ونتيجة لتفاقم مشكلة مقاومة المضادادات الحيوية

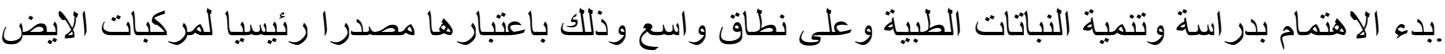

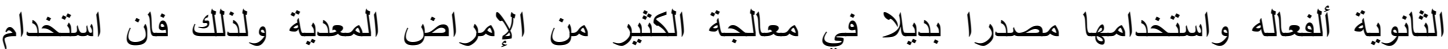

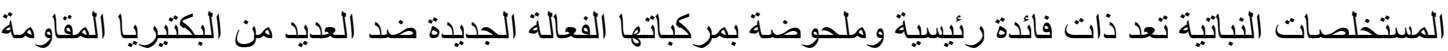

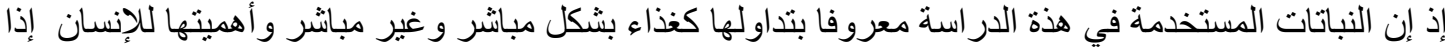
جاء اختبار النباتات الثثلاثة كونها من النباتات الواسعة الانتشار في العراق إضافة التافة إلى كون نباتي الزيتون

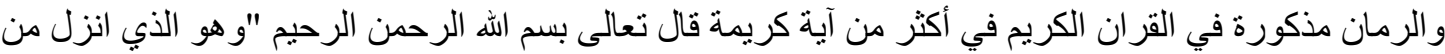

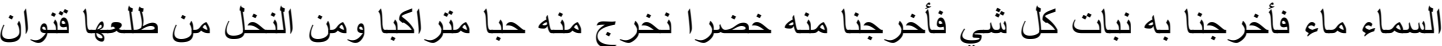


دانية وجنات من أعناب والزيتون والرمان مشتبها و غير متثابه .انظروا إلى ثمره إذا أثثر وينعه إن في ذلكم

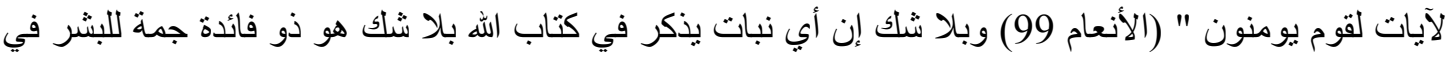

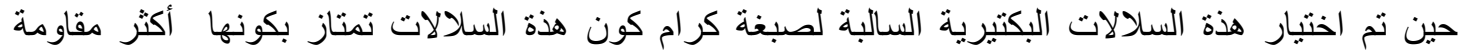

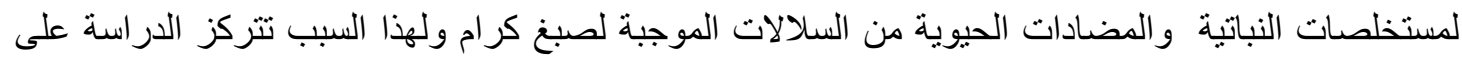

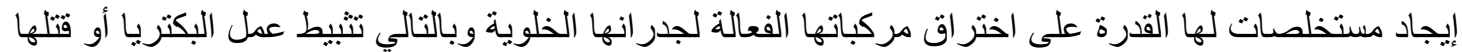

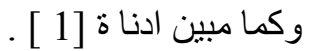

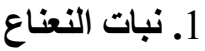

يعتبر النعناع Mentha longifolia من النباتات التي /ختريت لانتشارها في العراق إذ إن الأجزاء المستعملة

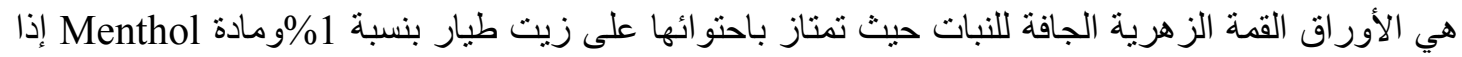

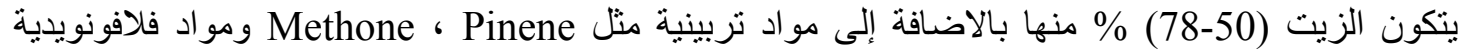

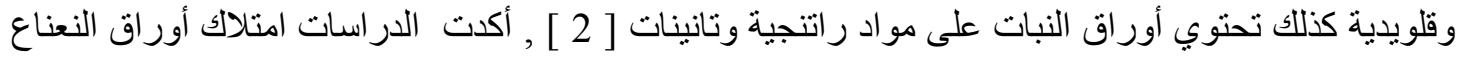

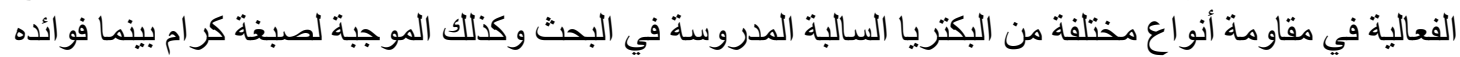

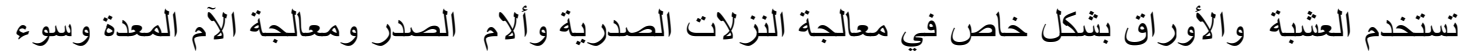

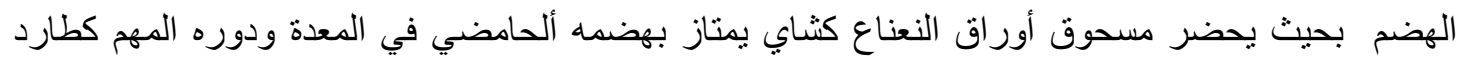

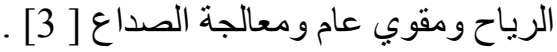

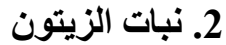

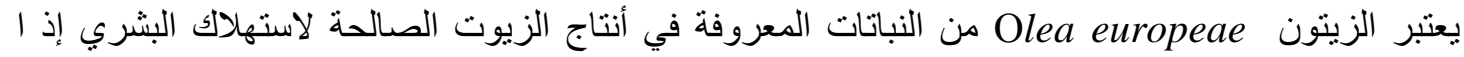

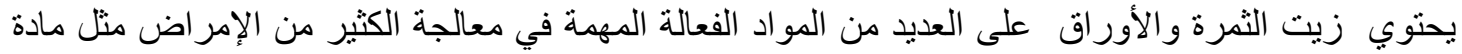

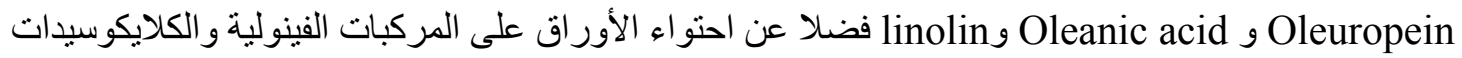
و الفلافونيدات, في حين وضحت الدراسات السابقة امتلاك أوراق الزينون فعالية تجاة نفس السلالات المدروسة

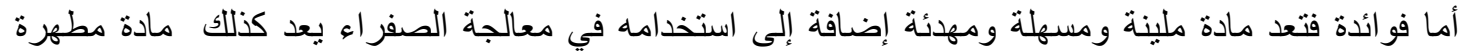

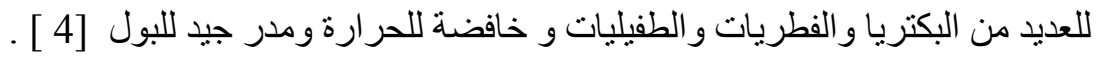

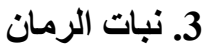

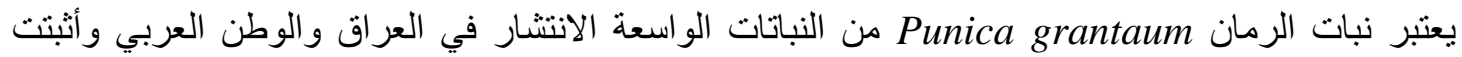

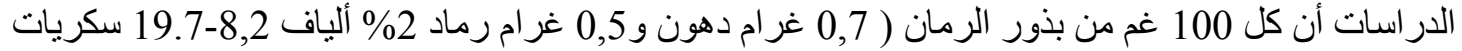

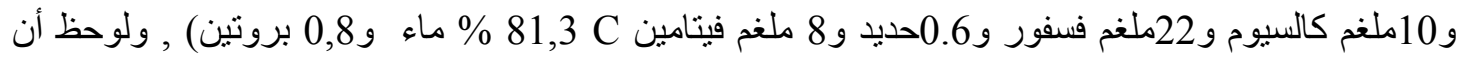

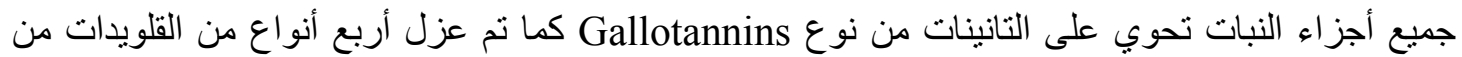

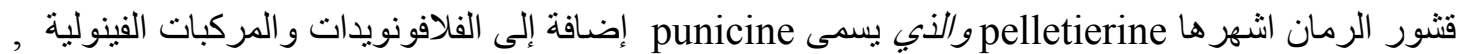

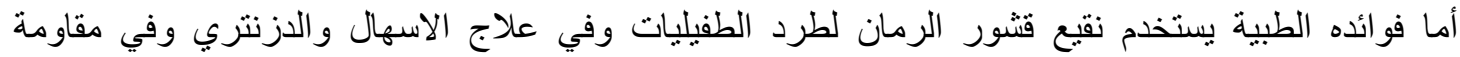

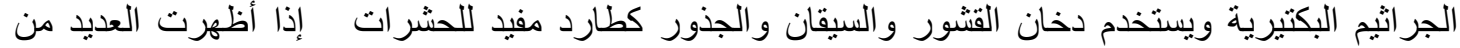

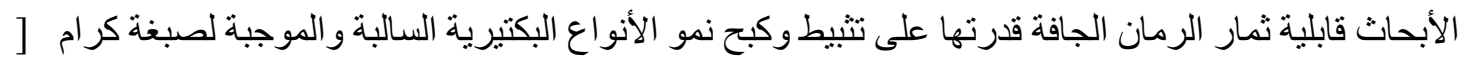

[ [ 5 ، 2

\section{المواد وطرائق العمل \\ جمع العزلات البكتيرية}

تم الحصول على العزلات البكتيرية المختبرة والمشخصة من مختبر الأحياء ألمجهريه التابع لقسم التقنيات

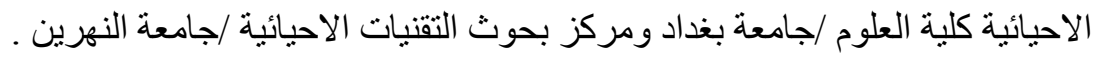

جمع العينات التباتية

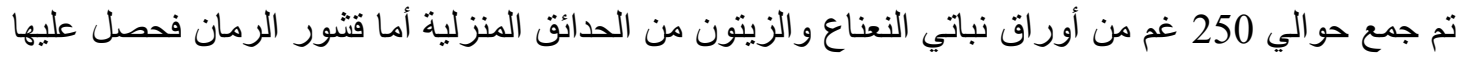

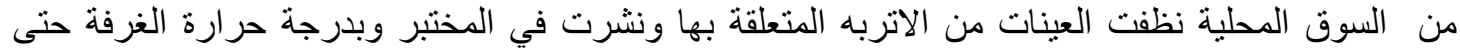
الجفاف آما قشور الرمان فأخذت جافة وبعدها طحنت بمطحنة نظيفة .تم تصنيف النباتات في قسم علوم الحياة 


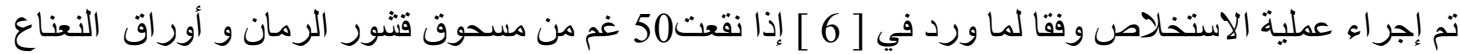

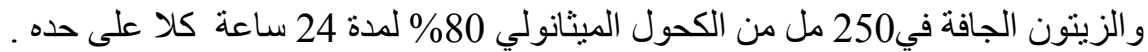
ثم أجريت عملية الاستخلاص لمدة8 ساعات في جهاز الاستخلاص المستمر السوكسليت (soxhlate) وبعدها رشحت جميع المستخلصات باستخدام ورق ترشيح و اتمان رقم واحد ثم ركزت باستخدام المبخر الدوار لعapator الاستخدام وحضرت منها التراكيز (10 ،25 ،50) ملغم/ مليلتر باستخدام الماء المقطر .عقم المستخلص

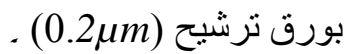
الكثف الكيميائي:

تم دراسة الكثوفات التمهيدية عن المركبات ألكيميائيه التي يحتمل وجودها في المستخلصات الميثانولية لقثور

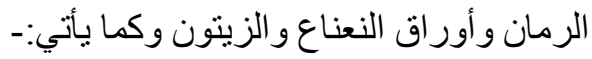
الكثف عن الكلايكوسيدات

اتبعت طريقة كاشف كيد ألوارده في [ 7 [ ] كثف عن عن الكلايكوسيدات والذي يعطي لون ازرق البنفسجي في

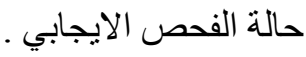
الكثف عن الفلافونات اعتمدت الطريقة الواردة في [ 8 [ ] الذي يظهر اللون الأصفر دليل على ايجابية الفحص . الكثف عن الراتنجات تبعت الطريقة المذكورة في [9 9] لكثف عن الر اتتجات و التي يكون فيها عكوره دليل على وجود المواد الر اتنجية الكثف عن التانينات اتبعت الطريقة الواردة في [ 10] أذان ظهور اللون الأخضر المزرق دليل على وجود التانينات . الكثف عن الصابونينات اعتمدت الطريقة الواردة [ 9 ] الاستدلال على وجود الصابونينيات بظهور رغوة كثيفة تبقى لفترة طويلة .

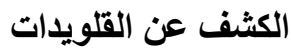
تم الكثف عن القلويدات حسب طريقة [ 11] وذلك باستخدام كاثف در اجندروف الذي يكون راسب برتقالي عند

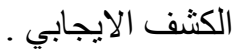
الكثف عن الزيوت الأساسية اعتمدت الطريقة الكثف عن الزيوت الأساسية كما ورد في[ 12 ] حيث يدل اللون الوردي البراق على وجود

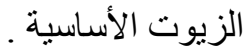
الكثف عن الفينولات المتعددة

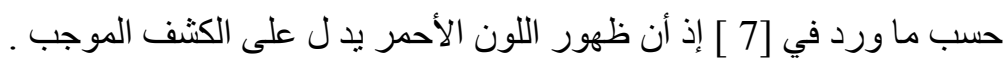

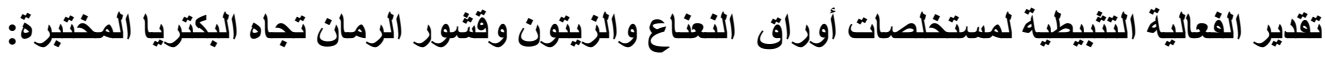

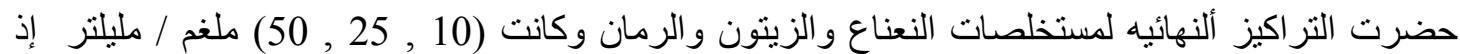

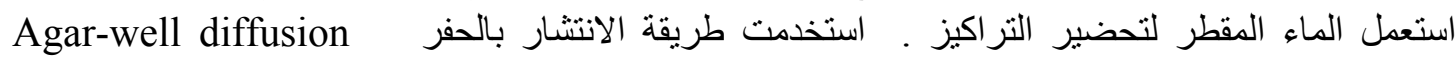
لملاحظة تأثير المستخلصات تجاة البكتريا , تم اختبار الفعالية التثبيطية لمستخلصات النباتية كما ورد في [13] بإضافة 0,1 مل من عالق البكتريا , Pseudomonas aerugenosa , Serratia marcesens Escherichia. coli, Proteus vulgaris , Klebsiella pnemunoniae طبق الأكار التحضيري ثم نشرت على سطح الطبق وعملت أربعه حفر في كل طبق , قطر كل حفرة 6 ملم

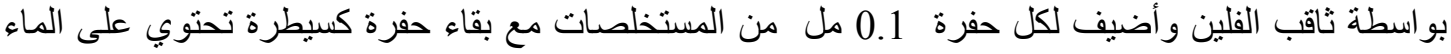
المقطر المعقم فقط وبعدها حضنت الأطباق بدرجة حرارة 37 مئوية ولمدة 18-24 ساعة , حددت الفاء الفعالية

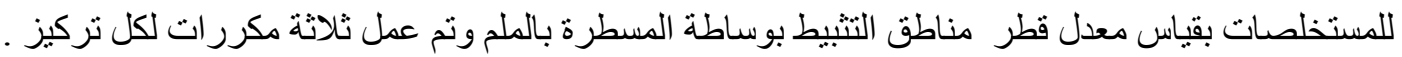


التحليل الإحصائي

حلت النتائج بالاعتماد على المقارنات المتعددة بين المعادلات المعاملات ألداخله في التجربة التامة التعشيه complete randomized design ( CRD) الفرو قات بين المعاملات وحساب الاختلافات المعنوية بينها و عند مستوى 0.05 كما ورد في [14 ] .

جدول (1) : يوضح نتائج الكثف العام عن المركبات الكيميائية الفعالة في المستخلصات الكحولية لاوراق النعناع والزيتون وقثشور

\begin{tabular}{|c|c|c|c|}
\hline متخلص قثور الرمان & مستخلص أوراق الزيتون & مستخلص أوراق النغناع & المكونات الفعالة \\
\hline+ & + & + & الكلاكوسيدات \\
\hline+ & + & + & التانينات \\
\hline+ & + & + & الزيوت الطيارة \\
\hline+ & + & + & الفلافونات \\
\hline+ & + & - & الصابونينات \\
\hline+ & + & $\overline{+}$ & متعدد الفينول \\
\hline+ & + & + & الراتنجيات \\
\hline+ & + & + & القلويدات \\
\hline
\end{tabular}

الزمان

يبين جدول (1) احتواء النباتات المدروسة على اغلب مركبات الايض الثانوي الفعالة كافة عدا الصابونينيات في

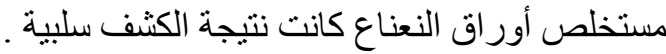

1. تقدير الفعالية التثبطية لمستخلص أوراق النعناع Mentha longifolia في نمو العزلات البكتيرية

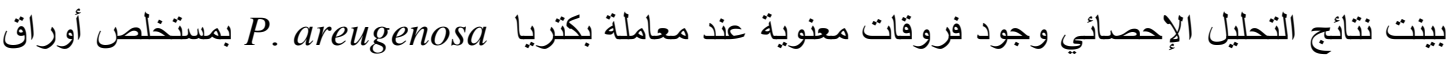

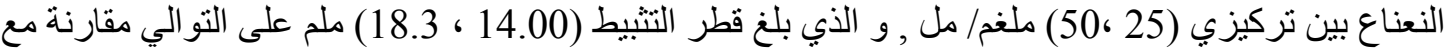

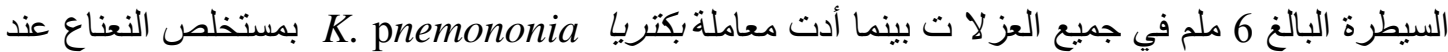

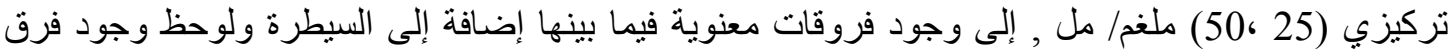
معنوي أعلى عند التركيز 50 إذا بلغ قطر التنبيط 14.67 ملم مقارنة مع السبطرة , في حين كانت معاملة بكتريا S. marscens E.coli

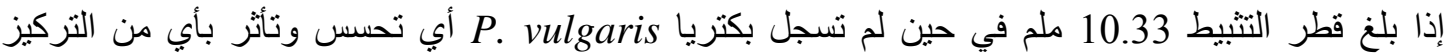
الكحولية كما موضح في جدول (2) .

جدول (2): تأثيرمستخلص أوراق النغناع في نمو العزلات البكتيرية السالبة لصبغة كرام المختبرة المقاس بالميليمتر ( SE

(Mean

\begin{tabular}{|c|c|c|c|c|c|c|}
\hline المستخلص & التركيز ملغم|مل & P.aerugenosa & K.pnemononia & E.coli & P.vulgaris & S.marscens \\
\hline \multirow{3}{*}{ النعناع } & 25 & a $14.00 \pm 3.51$ & a $11.33 \pm 0.66$ & a6.33 \pm 0.33 & a $6.00 \pm 0.00$ & a $6.67 \pm 0.00$ \\
\hline & 50 & a $18.33 \pm 1.453$ & b $14.67 \pm 0.882$ & $b 10.33 \pm 0.66$ & a $6.00 \pm 0.00$ & b $10.33 \pm 0.66$ \\
\hline & control & b $6.00 \pm 0.00$ & c $6.00 \pm 0.00$ & $a 6.00 \pm 0.00$ & a $6,00 \pm 0.00$ & a $6.00 \pm 0.00$ \\
\hline
\end{tabular}

* الحروف الصغيرة المتثابهة تغني عدم وجود فروقات مغنوية بين التراكيز عند مستوى احتمالية (0.05) في الصف الواحل كل على

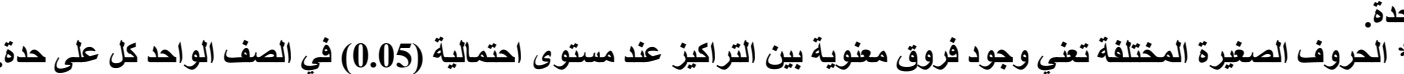

2. تقلير الفعالية التثبية لمستخلص أوراق الزيتون Olea Europea في نمو العزلات البكتيرية

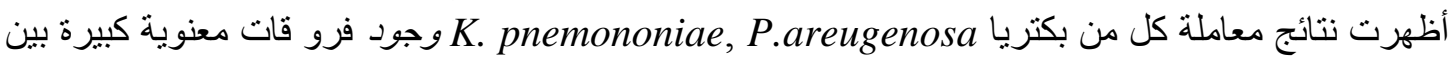
تركيزي 50,25 ملغم/ مل اذا بلغت 15.33 ملم مقارنة مع السبطرة البالغة 6 ملم , في في حين أظهرت معاملة

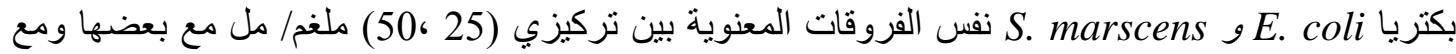

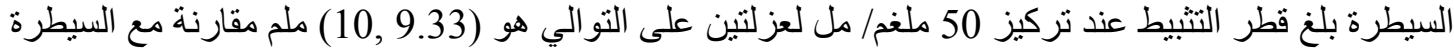

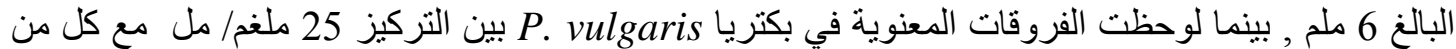

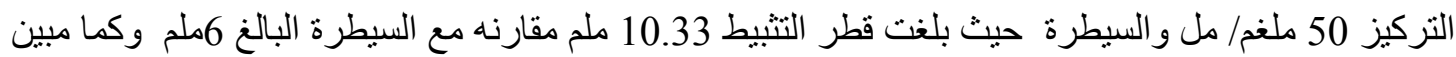


ج SE ) جدول (3) :تأثيرمستخلص أوراق الزيتون في نمو العزلات البكتيرية السالبة لصبغة كرام المختبرة المقاس بالميليمتر

(Mean

\begin{tabular}{|c|c|c|c|c|c|c|}
\hline المستخلص & التركيز ملغم/مل & P.aerugenosa & K.pnemononiae & E.coli & P.vulgaris & S.marscens \\
\hline \multirow{3}{*}{ الزيتون } & 25 & a $15.33 \pm 0.66$ & a $13.67 \pm 0.66$ & a $8.00 \pm 0.00$ & a $10.33 \pm 0.33$ & A $7.00 \pm 1.00$ \\
\hline & 50 & a $15.33 \pm 1.85$ & a $15.33 \pm 0.88$ & b $10.00 \pm 1.00$ & b $6.00 \pm 0.00$ & B $9.33 \pm 0.33$ \\
\hline & control & b $6.00 \pm 0.00$ & b $6.00 \pm 0.00$ & c $6.00 \pm 0.00$ & b $6.00 \pm 0.00$ & C $6.00 \pm 0.00$ \\
\hline
\end{tabular}

*الحروف الصغيرة المتثابهة تعني عدم وجود فروقات معنوية بين التراكيز عند مستوى احتمالية (0.05) في الصف الواحد كل على

* الحروف الصغيرة المختلفة وجود فروقات معنوية بين التراكيز عند مستوى احتمالية (0.05) في الصف الواحد كل على حدة.

3.تقدير الفعالية التثبيةية لمستخلص قشور الرمان punica granataum في نمو العزلات البكتيرية

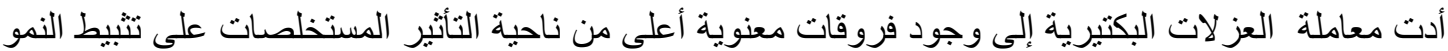

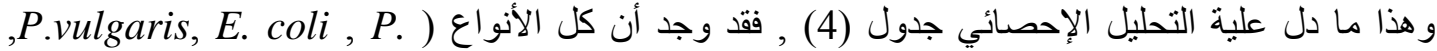
(areugenosa ,K.pnemnoniae, S.marscens لها فروقات مع بعضها بين تركيزي (25) ، 250 السيطرة فقد بلغ قطر التثبيط عند التركيز 50 ملغم/ مل هي (13,18,18.33,21) ملم مقارنة مع السيطرة البالغ (6) ملم , أما بكتريا P.vulgaris فلم تكن هنالك فروقات معنوية بين التركيز (25) و السيطرة بينما كانت هناك فرق معنوي إذ بلغ قطر التثبيط 9.33عند التركيز 50 ملغم/ مل .

ج SE ) بلول (4) تأثيرمستخلص قثور الرمان في نمو العزلات البكتيرية السالبة لصبغة كرام المختبرة المقاس بالميليمتر

(Mean

\begin{tabular}{|c|c|c|c|c|c|c|}
\hline المستخلص & التركيز ملغم/مل & P. aerugenosa & k.pnemononiae & E.coli & P.vulgaris & S.marscens \\
\hline \multirow{3}{*}{ الرمان } & 25 & a $20.00 \pm 0.00$ & a $16.67 \pm 0.33$ & a $15.33 \pm 0.88$ & a $6.00 \pm 0.00$ & a $11.33 \pm 0.33$ \\
\hline & 50 & b $21.33 \pm 0.88$ & b $18.33 \pm 0.66$ & b $18.00 \pm 1.52$ & b $9.33 \pm 0.33$ & b $13.00 \pm 1.15$ \\
\hline & control & c 6. $60 \pm 0.00$ & c $6.00 \pm 0.00$ & c6.00 \pm 0.00 & a $6.00 \pm 0.00$ & c $6.00 \pm 0.00$ \\
\hline
\end{tabular}

* الحروف الصغيرة المتشابهة تعني عدم وجود فروقات معنوية بين التراكيز عند مستوى احتمالية (0.05) في الصف الواحد كل على

*الحروف الصغيرة المختلفة وجود فروقات معنوية بين التراكيز عند مستوى احتمالية (0.05) في الصف الواحد كل على حدة.

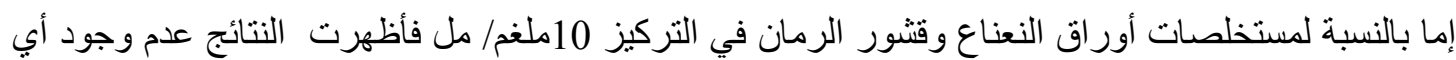
تأثير لانواع البكتيرية بها ـ بينما تأثرت كل من بكتريا E. aerugenosa و و

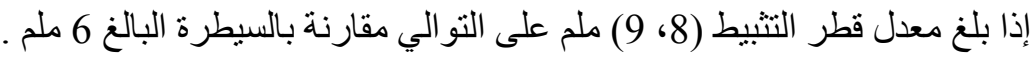

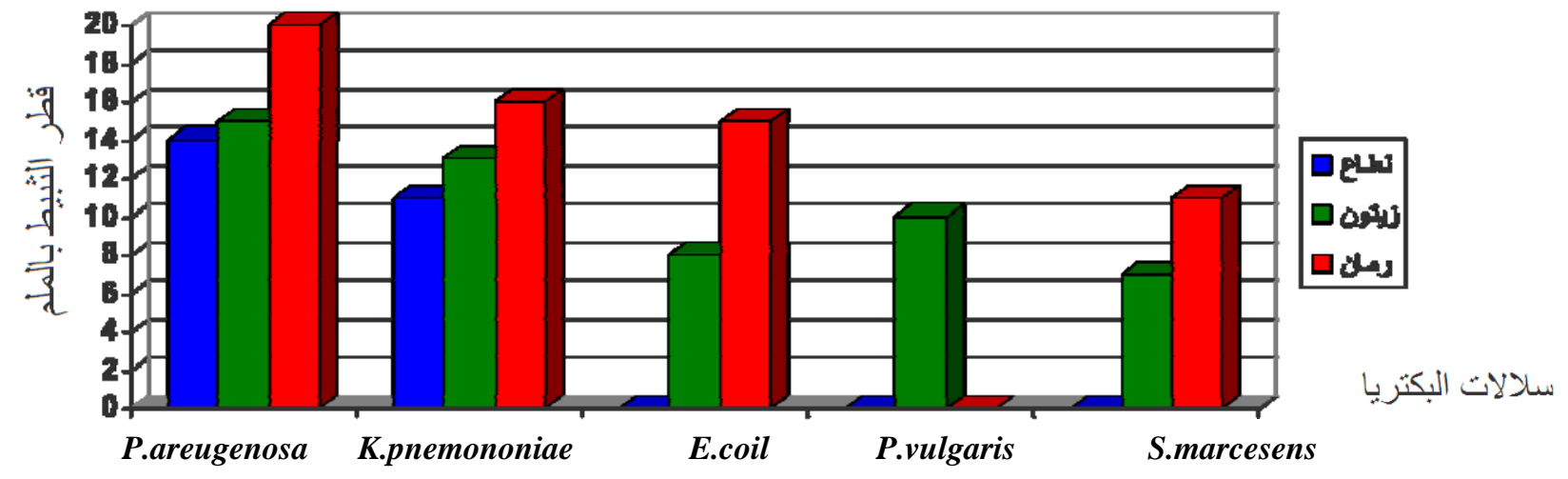

شكل (1): يوضح العلاقة بين السلالات البكتيرية وقطر التثبيط الناتجة من تأثير

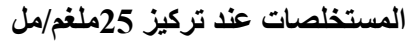

شكل (1) يبين أن أفضل المستخلصات بقدرتها على التنبيط هو مستخلص أوراق الزيتون ضد نمو الأنواع

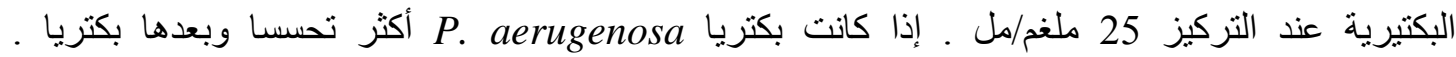
K pnemononiae

$$
\text { فيما كان مستخلص أوراق النعناع اقلهم تأثثرا على العز لات البكتريا . }
$$




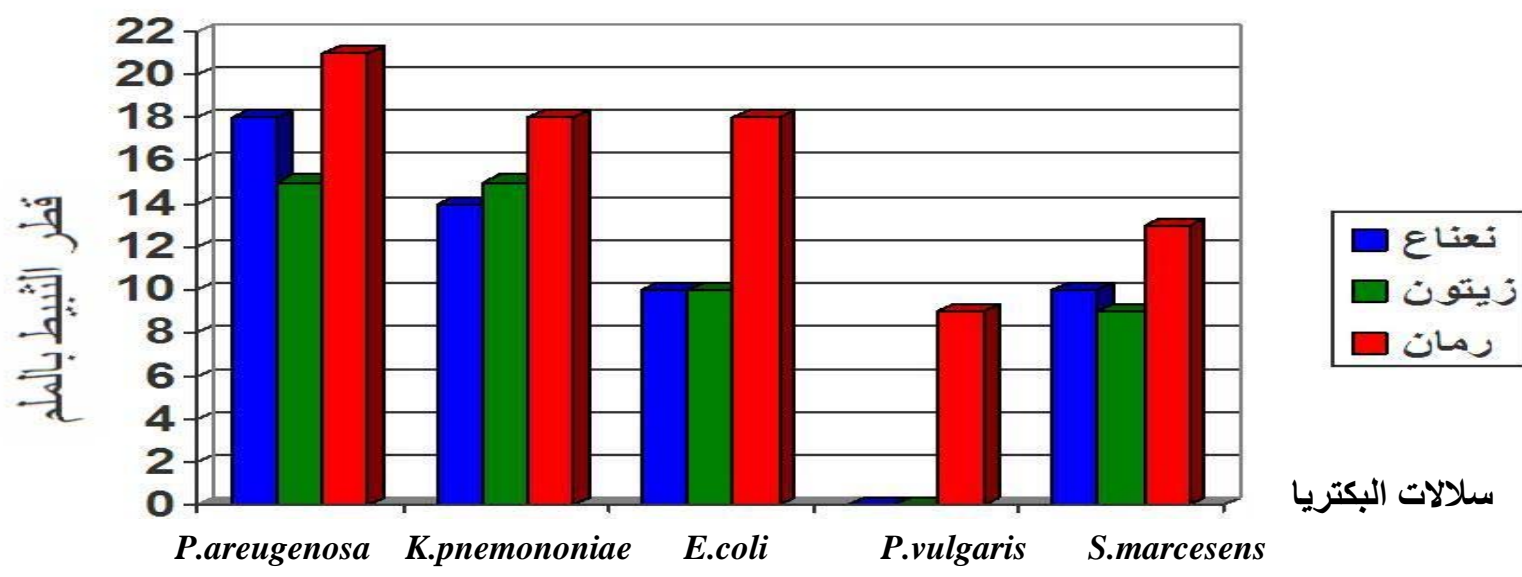

شكل (2): يوضح العلاقة بين السلالات البكتيرية وقطر التثبيط الناتجة من تاثير المستخلصات عند تركيز50ملغ/مل

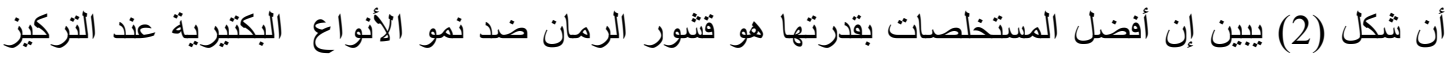

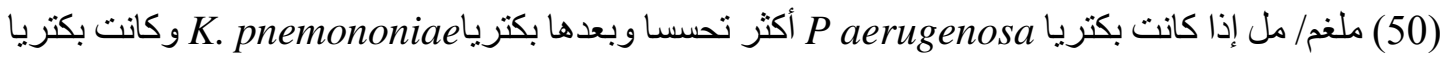

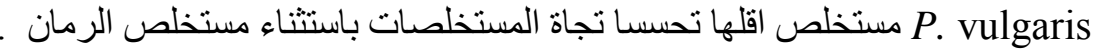

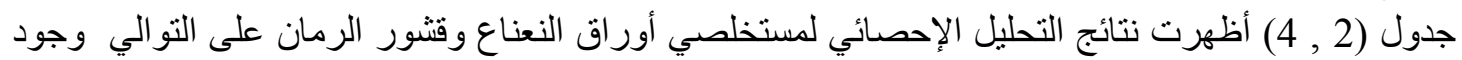

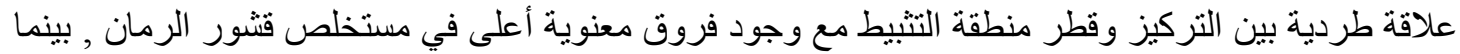

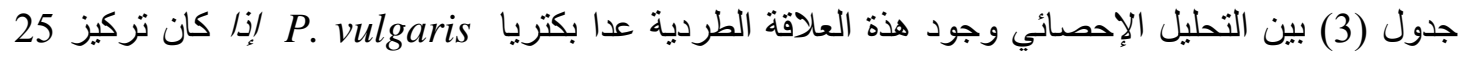

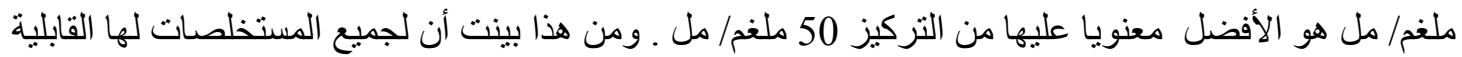

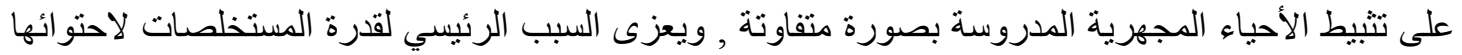

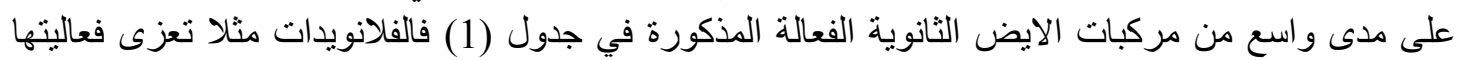

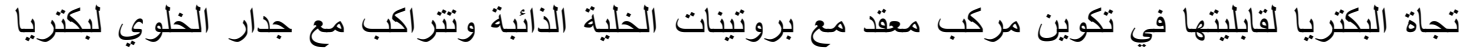

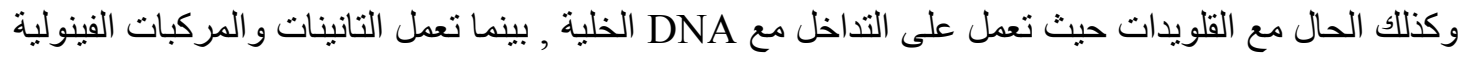

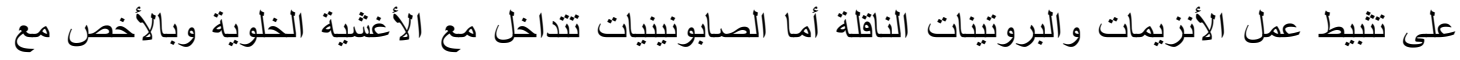
ستيرو لات الغثاء الخلوي وتعمل على تحليل الخلايا الحية [1، 15 ] ] ل

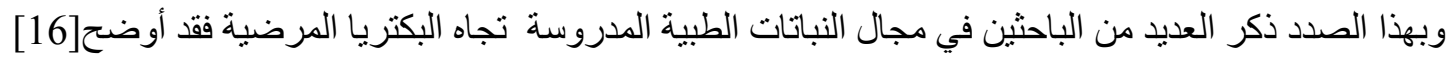
أن مادة المنثول Menthol وزيت النعناع الموجود في الأوراق لها قابلية منوسطة في التأثير في الأنواع النياع

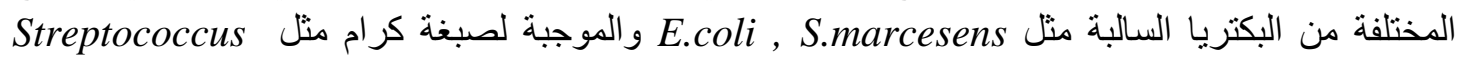
ك. S.pyrogen arueus,

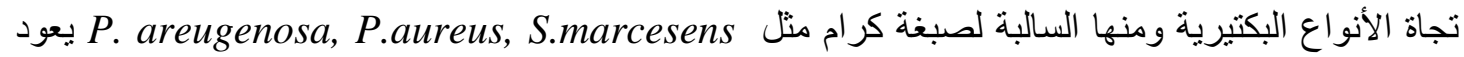

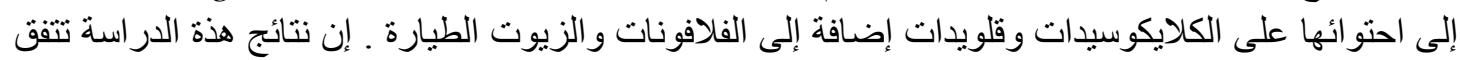

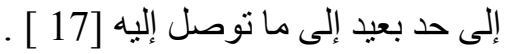

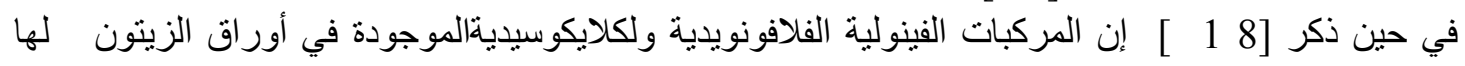

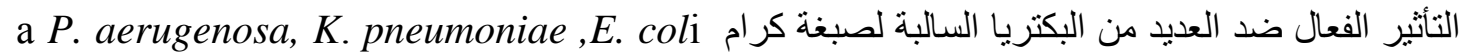

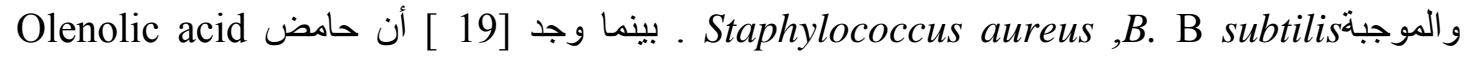

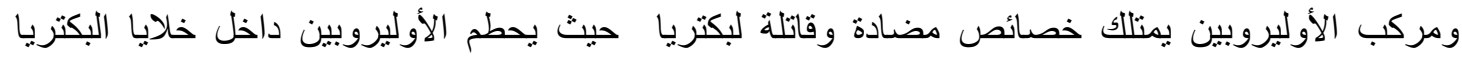
لإنتاج Olenolic acid المعروفة بفعاليته تجاه الأحياء المجهرية والذي يخترق الخلايا المضيفة مسببه تتبيط

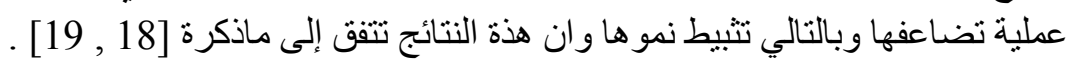
وجد [20] إن التانينات الموجودة في القنشور و الثمار والسيقان و هي من نوع و

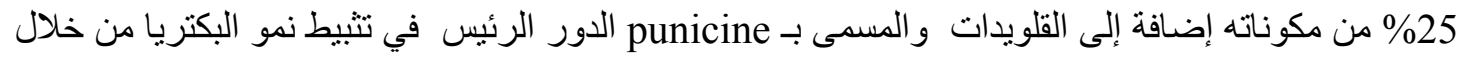

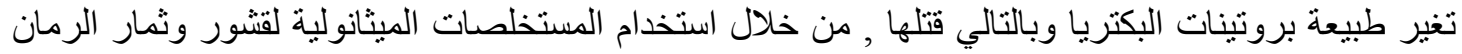

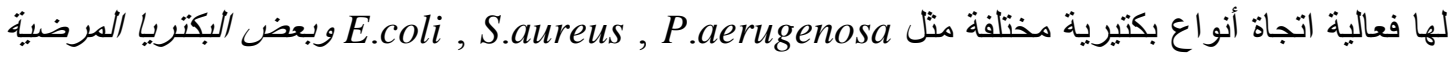


التي تصبي الأمعاء Salmonella.typhi, shigelle . paradysentria بينما [21] [بين أن لهذة المستخلصات القدرة على تثبيط نمو أنو اع أخرى مثل Pاء إلى ما ذكر ة وتوصل إليه كل من [21,20 ]

المصادر

1. Al-bayati,f.A and Almola .H.f . (2008) Antibacterial and Antifungal activity of different parts of Tribulus Terrestris L.growing in Iraq.J. zhejiang.univ.Sci .9(2):154-159

$$
\text { 2. قطب . فوزي طه ـ (1981) النباتات الطيبة زر اعتها ومكوناتها , دار المريخ للنشر , الرياض , }
$$

3. Essawi,T;sour,M.(2000):screening of some plestian medicinal plants for antibacterial activity .J.Ethanopharmacol,70:343-349

4. Markin,D;Duke,L.;Berdicevsky(2003),I. In vitro antimicrobial activity of Olive Leaves .Mycoses ,46,132-136

5. Machado, T.B,. Leal, C.R., Amerl, A, C. F., Santos, K.R.N., silva, M.G. and Kuster, R.M.(2002) :Antimicrobial ellagitannin of Punica granatum fruits. Journal of Brazilian Chemical Society, 13; 606-610

6. Harborn, V. B.(1973) phytochemical methods, A guide modern techniques of plant analysis. Chapmen Hall. London.

$$
\text { 7. الثحات ,نصر ابوزيد 1986,النباتات و الإعشاب الطبية.دار البحار .بيروت A. A. and Alnaib. A, }
$$

8. Jaffer, H.L; Mahmed M. j ; jawad. A.M; naji. A. and Alnaib. A. 1983. phytochemicaland biological screening of some Iraqi plant . fitoterapia. Pp. 299.

9. Shihata,I.M.(1951): A pharmacological study of Anagllis arvensis .Msc.thesis Faculty of vet. Med. Cairo University Egypt.

$$
\text { 10. دلالي ,باسل كامل و الحكيم, صادق حسن 1987,تحليل الأغذية .مطبعة دار الكتب .جامعة الموصل. }
$$

11. Fahmy,I.R(.1933).constituents of plant crude drug . $1^{\text {st }}$. Ed Barby.Cairo.

12. Hand,S.S,Mandkinajedd,D and Man gal .A.K .(1998).Indian Herbal pharmacopoeia, vol 1 .pub India drug manufactures Assoc and Regional res. Mumbi.

13. Perez , c ; pauli ;M ; Bazerque , $P$;(1990) :Antibiotic assay by ager well diffusions method, A ct boil.med.Exp,15;113-115.

$$
\begin{aligned}
& \text { 14. الساهوكي ,مدحت و و هيب ,كريمة محمد ,1990 .تطبيقات في تصميم وتحليل التجارب .مطبعة } \\
& \text { دار الحكمة لطباعة والنشر ,الموصل. }
\end{aligned}
$$

15. Naida,A.S.bidlack;W.R. and Crceline ,(2000). hytoantimicrobials in :natural food Antimicrobial System Aidu, A.S .eds, CRC New York, 325-417.

16. Diaz,R; Quevedo-Sarmiento ,j; Ramos-cormenzana ,A;Cabo, j .(1988): phytochemical and antibacterial screening of some spiecies of Spanish Lamiaceae. Fitoterapia, 59:330-333.

17. Bupesh,G; Amutha,C;Nandagopal,S; Ganeshkumar,A.; Sureshkumar, P; Saravana mural,K. (2007): Antibacterial activity of Mentha pipertal (peppermint) from leaf extract-a medicinal plant J. Agriculture Slovenian.1 (89) 73-79.

18. Pereir -Ana, p; Ferreira, c.F.R;Isabel, Marcelino, f. Valentao, p ; Andrade. p. b; seabra,R. Estevinho; bento,A and pererira,j.A.(2007) Phenolic compounds and antimicrobial activity of Olive Leaves .j.Molecules. 12,1153-1162. 
19. ALazzawy Hassan (2004), Biochemical and Biological studies on Oleurpein and its Hypoglycemic Effect, A thesis submitted to Department of chemistry college of science of Baghdad university.

20. Pradeep,B.V,Manojbaba,M.k; and Palaniswamy,M.(2008): Antibacterial Activity of Punica granatum L. against Gastro Intestinal Tract Infection Causing Organisms .j. Ethnobotanical Leaflets. 12: 1085-89..

21. Prashanth, D., Asha, M.K., Amit, (2001):A. Antibacterial activity of Punica granatum. Fitoterapia, 72; 171-173. 